\title{
Meta Cognition Thinking and Its Relationship to Patterns of Brain Dominance among Jordanian University Students According to Gender and Specialization Variables
}

https://doi.org/10.3991/ijet.v16i13.21999

\author{
Hussain Muhammad Aburayash \\ Arab Open University, Amman, Jordan \\ H_aburaiyash@aou.edu.jo
}

\begin{abstract}
The study aimed to identify the level of Meta Cognition thinking and its relationship to dominant patterns of brain dominance among Jordanian university students, and to identify if there were differences in the level of Meta Cognition thinking and brain dominance patterns attributed to variables of gender and college. The study sample consisted male and female students at the academic year 2020/2021, and this sample was taken in a simple random way. Two measures were applied: Meta Cognition thinking, and brain dominance patterns, after confirming their psychometric properties. The results showed that the level of Meta Cognition thinking among Jordanian university students is (high), and that the dominant brain pattern among the study sample is the right pattern, followed by the left and then the integrated, and also there is no statistically significant relationship between the brain dominance patterns and the variables of gender and college, and there is statistically significant differences in Meta Cognition thinking among students with the (left) brain dominance pattern compared to those with the (integrated) brain control pattern and in favor of those with the left brain dominance type.
\end{abstract}

Keywords-Meta cognitive, Brain dominance

\section{Introduction}

Many thinkers in the field of research and study have studied thinking in its various types, and they employed the knowledge that generate from their research in the field of education at various levels and stages of study, in order to create a generation of learners capable to think and adapt to the requirements of the twenty-first century with its various and accelerating variables.

The researches dealt with Meta Cognition thinking, that is happens in the brain cortex, which means our ability to know what we know and what we do not know, and our ability to plan a strategy in order to produce the necessary information, and to be aware of our steps and strategy during the problem-solving process, and to reflect on the extent of productivity of our thinking and evaluate it. It is well known that the 
internal language, which is believed to be a pre-requisite for Meta Cognition thinking, begins to appear in children at the age of five, and despite this, Meta Cognition thinking constitutes a major characteristic of systematic thinking [1].

\subsection{Meta cognition thinking}

Meta cognitive thinking is a complex psychological concept due to the difficulty of measuring it directly. It deals with a number of concepts such as Meta Memory, Meta Perception, and Meta Cognition. It includes an active monitoring of cognitive processes through Planning, monitoring, understanding and evaluation of task performance [3]. This is confirmed by [4]. That the individual's understanding and conscious thinking of the mechanisms of what he does leads to a reduction in the time and effort required to achieve the goals.

Illustrates the importance of Meta Cognition thinking and its effectiveness in the educational process, which seeks to achieve several goals, including[1]: enabling the learner to develop an action plan in his mind for a period of time, reflecting on and evaluating it after its completion, and facilitates the process of making interim judgments, comparing and evaluating learner's readiness to undertake other activities. [5] emphasized that learners with Meta Cognition thinking use discovery strategies, as they gain more in-depth knowledge and better performance, because these strategies allow them to plan and evaluate their learning.

Many studies have been conducted that dealt with the relationship between Meta Cognition thinking and many variables. Including variables of gender, discipline and academic achievement. A [6] study has shown that the level of Meta Cognition thinking among students of human disciplines is better than the level of Meta Cognition thinking among students of scientific disciplines. With regard to the academic achievement variable, a [7] study showed that students who possess a high level of Meta Cognition thinking have high academic achievement.

According to the brain theory (the neural direction), the analogy between thinking and learning, as learning is thinking, and thinking occurs in the brain cortex, whether it is on the left side or the right side of the brain. The neural trend emphasized that thinking (learning) occurs as a result of an actual physical growth of the brain. Talking about learning means talking about thinking, and talking about thinking means talking about the physiology of the brain, and how to increase the physical growth of the brain, and thus increase the learning, which means increase the thinking [8]- [9], [10].

\subsection{Brain dominance}

Brain dominance is one of the factors contributing to the educational process, especially if the learning environment is designed to influence students' different learning styles. Through students' brain control that the perception process, the information processing process, and their learning styles can be understood.

Information is received and processed through the human nervous system, which consists of two subsystems, one of which includes the nerves spread in the viscera and 
the senses and the nerves that drive the muscles, and the other central includes the brain and spinal cord, where the human brain contains more than a hundred billion nerve cells, and more than fifty thousand nerve links between the ends of one nerve cell and the end of another nerve cell, where information is stored in these cells and connections [11].

The studies about brain physiology resulted that the brain consists of two halves (left and right) that connect together with a group of nerves called (Corpus Callous), which works on passing nerve signals between the two halves of the brain [10].

Each of [12], [13] indicates that the relationship between the two halves of the brain is mutually complementary, and that each half is specialized in processing certain types of information. This is explained by [14] that the brain dominance of the two halves is as the left half processing linguistic, analytical, abstract, temporary, numerical and logical information, and that the right hemisphere processes the nonverbal, spatial, intuitive, holistic and symbolic information and emotion, creativity and imagination.

Some reported that the left-brain half of (85-90\%) of individuals is the controller and dominant, while for (10-15\%) it is the right half. Also [15],[16] and indicated that many individuals use both sides of the brain in a holistic way in thinking and learning more than they depend on a certain half [24]. Believes that the importance of brain dominance appears through its association with individuals' thinking style and school curriculum, in addition to choosing professions and academic disciplines, as individuals choose professions and academic branches based on the compatibility between their learning and thinking patterns, and the control of one of the two brain halves [17].

A [18] study on a sample from different academic disciplines showed that humanities students tend to be the right-brain half is the dominant, while students of natural sciences tend to be the left-brain half is the dominant. The results of [19] study also showed a statistically significant impact of brain dominance on choosing discipline, and those students of artistic / literary majors prefer to use the right-brain half, while students of business administration discipline use the left-brain half, and that students of education, nursing, communication and law disciplines were right-brain half users, and students of engineering and science majors were left-brain half users.

Many of the results of studies, such as studies of [20], [21] that were focused on the two brain halves, and which focused on the dominant thinking patterns of school and university students based on the functions of both halves of brain, indicate that the education process focuses on the analytical thinking pattern, language and mathematical logic, and these are among the functions of the left-brain half, while the functions of the right-brain half, represented by visual, spatial, intuitive, structural, holistic and totalitarian thinking are in decline [22].

The brain is the center of human thinking and emotions, as it represents the center of command and control that a human use in solving his problems and carrying out planning processes. Thus, studying the human brain is considering as a path towards various knowledge and information about human capabilities, to be used in progress and development in various fields [23] and [16] indicated the possibility of determining the pattern of brain dominance for individuals through applying psychological 
tests to measure brain dominance, such as (Torrance, Mc-carthy, Herman) tests, as well as through radiography.

Many studies have focused on studying brain dominance and its relationship to thinking among university students, due to the great importance and its relationship with affects their university life and their future. As a [25] study, which showed that the level of Meta cognition thinking among university students was middle, and that there were no differences in the level of Meta cognition thinking among students attributed to the variable of gender and college. A [26] study that conducted on preparatory year students at the University of Hail in Saudi Arabia indicated that the integrated pattern is the dominant pattern among them, and that there were statistically significant differences in using the left-brain half between the students with excellent achievement and those with middle achievement in favor of the outstanding students. A [27] study showed that the level of Meta Cognition thinking was middle among a sample of Baghdad University students, and that there were no statistically significant differences in the level of Meta Cognition thinking attributed to the variables of gender and specialization.

[28] also conducted a study aimed at identifying the level of Meta Cognition thinking among students of Yarmouk University in Jordan according to some variables, on a sample of students in the scientific and humanitarian colleges. The results showed that there are statistically significant differences in the level of Meta Cognition thinking due to the level of achievement in favor of those with high achievement, and differences attributable to the variable of specialization and in favor of the human faculties. The [29] study also showed that there were no statistically significant differences between a sample of female students at King Saud University in Riyadh in their brain dominance pattern according to their different specializations.

\subsection{Problem of the study and questions}

The interest in recognizing the level of Meta Cognition thinking among university students has become an urgent necessity, in addition to the fact that the two brain halves theory is one of the relatively modern theories in learning, and it is also important for university professors to be aware of the thinking level of their students, and the pattern of brain dominance prevailing for them, which helps them to planning to implement appropriate cognitive programs and activities to implement the academic courses. Therefore, this study seeks to answer the following questions:

1. What is the level of Meta Cognition thinking among Jordanian university students?

2. Is there a statistically significant relationship at the level of significance $(\alpha=0.05)$ between the arithmetic means of the estimates of the study sample members on the Meta Cognition thinking scale due to the college variable?

3. What is the prevailing pattern of brain dominance among Jordanian university students?

4. Is there a statistically significant relationship at the level of significance $(\alpha=0.05)$ between the brain dominance pattern of Jordanian university students according to the student's college (human, scientific)?

5. Does Meta Cognition thinking differ as a whole with the type of brain control? 


\subsection{Importance of study}

The theoretical importance of the study stems from its dealing of the subject of Meta cognition thinking and its relationship to the pattern of brain dominance among Jordanian university students, which has occupied many researchers in the psychological, educational, medical and physiological fields at the global level, and who did not reach consistent results from which they can formulate applicable evaluations. This study is expected to contribute, at least in part, to the scientific knowledge obtained in previous studies.

In practice, it is expected that the results of the study will contribute to raising the awareness of university professors and students about the importance of planning for cognitive activities for the two brain halves and their integration, and how to employ them in developing Meta Cognition thinking skills.

\subsection{Study determinates}

The study is limited to a sample of students at the University of Jordan and students of the Arab Open University who are registered in the first semester of 2020/2021, and to the subjects of Meta Cognitive thinking and brain dominance, and the psychometric properties available for the study tools.

\subsection{Concepts definition}

Brain dominance:[4] defined it as the trend and tendency of the individual to use one of the two brain halves (left / right) or both together in processing information and behavior. The researcher defines it procedurally as it is the degree to which the study member gets on the scale of his brain dominance patterns (left pattern, right pattern, integrated pattern).

Meta Cognition thinking: It is the individual's awareness of his thinking processes and his strength in dominant of these processes [22]. The researcher defines it procedurally as it is the degree that the study member gets on the Meta Cognition thinking scale used in this study.

\section{Method}

\subsection{Participants}

The study sample consisted of (880) bachelor students at the humanities and science colleges at the University of Jordan and the Arab Open University, and table (1) shows the characteristics of the sample according to the faculty and gender (450 from humanitarian colleges, 430 from scientific colleges, and according to gender 460 males and 420 females). 


\section{$2.2 \quad$ Instruments}

Meta Cognition thinking scale: After reviewing the scales related to Meta Cognition thinking that were included in some previous studies, it was relied on Kumar [30], which consists of (52) paragraphs that measure (cognitive organizing, knowledge of cognitive, and cognitive processing).The validity of the scale was verified by presenting it to (15) faculty members who specialize in educational psychology, measurement and evaluation in Jordanian and Saudi universities. The researcher adopted a percentage of agreement (80\%) of arbitrators' opinions, and after taking the opinions of the arbitrators, (42) paragraphs were adopted, and the level of students' possession of Meta Cognition thinking skills was divided into categories according to the following criteria (1-1.79 very low, 1.80-2.59 low, 2.60- 3.39 medium, 3.40-4.19 high, $4.20-5$ very high).The stability of the scale was verified by extracting the coefficient of stability of internal consistency using the Cronbach alpha equation for the scale as a whole and for the three dimensions, and the values ranged between $(0.82$ $0.94)$, where the value of dimension of cognitive organizing was (0.94), the value of dimension of cognitive knowledge was (0.87), the value of dimension of cognitive processing was $(084)$, and the value of the scale as a whole (0.92), and these coefficients are considered acceptable coefficients for this study.

Brain dominance patterns scale: After the researcher examined the measures of brain dominance that some studies in this field have included it, which used the (Torrance, Mc-carthy, Herman) scales, and this study was based on the Torrance scale [31] Image (C) that is consisting of (28) items; in each paragraph, there are two phrases, each of which represents a function of one of the two brain halves, and the validity of the scale was verified by presenting it to (15) faculty members specialized in educational psychology, measurement and evaluation in Jordanian and Saudi universities. The researcher adopted an agreement percentage of (80\%) of the arbitrators' opinions.

The stability of the instrument was verifying by the repetition method, where the correlation coefficient between the scores of individuals in the two times of applying was (0.88), and the internal consistency coefficient was extracted in each pair of paragraphs on three degrees ( 1 / zero / zero), where the answer is given for right pattern, for example (1), and zero is given for the left and integral pattern.

\subsection{Procedures and data analysis}

Study procedures and statistical treatment: After preparing the study instruments, they began to be applied to the study sample through the Internet, and after collecting the information, it was analyzed by the Statistical Package Program (SPSS) version (20), the study questions were answered through the use of duplicates, percentages, and the Chi-Square test) ( For the numbers of students in each brain pattern and according to the variable of the college and the academic level, the arithmetic means and standard deviations were extracted to know the level of Meta Cognition thinking among the members of the study sample. 


\section{Results and Discussion}

Question one: The arithmetic means and standard deviations of the estimates of the study sample individuals were calculated for the paragraphs of the Meta Cognition thinking scale as a whole, and each of its fields (cognitive organizing, knowledge of cognitive and cognitive processing). Table (1) clarifies the results.

Table 1. The means and standard deviations of the estimates of the study sample estimate paragraphs of meta-cognitive scale

\begin{tabular}{|l|c|c|c|c|}
\hline \multicolumn{1}{|c|}{ The field } & SMA & SD & Rank & Level \\
\hline Knowing Knowledge & 3.69 & 0.64 & 1 & High \\
\hline Regulation knowledge & 3.63 & 0.62 & 2 & High \\
\hline Processing knowledge & 3.25 & 0.71 & 3 & High \\
\hline & 3.62 & 0.48 & & High \\
\hline
\end{tabular}

Highest degree (5), lowest degree (1).

It is noted from table (1) that the level of Meta Cognition thinking among Jordanian university students is (high), with an arithmetic mean (3.62) and a standard deviation (0.48). Where knowledge of cognitive came first, followed by cognitive organizing, then cognitive processing.

The researcher attributes this result to the reliance of Jordanian university students since the spread of Corona pandemic on an online learning and education, as they need to rely more on searching for the knowledge they need from various learning sources, and to the ability to organize their knowledge in order to reach good understanding and comprehension, which makes them seek to practice higher thinking skills, especially Meta Cognition thinking skills, as well as working for processing the information they acquire as a mental processing that requires practicing of Meta Cognition skills.

Question two: Calculation of frequencies, percentages, and chi-squared test for brain dominance patterns among Jordanian university students according to the difference of the college variable (human, scientific). Table (2) shows the results.

Table 2. Frequencies, percentages, and chi-squared test for brain dominance patterns among Jordanian university students according to the difference in the college variable (human, scientific).

\begin{tabular}{|c|c|c|c|c|c|c|}
\hline & & \multicolumn{2}{|c|}{ College } & \multirow{2}{*}{ Total } & \multirow{2}{*}{ Chi-Square } & \multirow{2}{*}{ e Level ofsig } \\
\hline & & Humanities & Scientific & & & \\
\hline \multirow{2}{*}{ Left Pattern } & $\mathrm{N}$ & 260 & 107 & 367 & \multirow[t]{8}{*}{2.691} & 0.251 \\
\hline & Percentage & 29.50 & 12.10 & 41.60 & & \\
\hline \multirow{2}{*}{ Right Pattern } & $\mathrm{N}$ & 150 & 257 & 407 & & \\
\hline & Percentage & 17.00 & 29.30 & 46.30 & & \\
\hline \multirow{4}{*}{ Integrated pattern } & $\mathrm{N}$ & 50 & 56 & 106 & & \\
\hline & Percentage & 6.00 & 6.10 & 12.10 & & \\
\hline & $\mathrm{N}$ & 460 & 420 & 480 & & \\
\hline & Percentage & 52.50 & 47.50 & $100 \%$ & & \\
\hline
\end{tabular}


It is noticed from Table (4) that the value of the statistical significance for the college variable $(0.251)$ is greater than the level of statistical significance $(\alpha=0.05)$, which indicates that there is no statistically significant relationship between the brain dominance patterns of Jordanian university students and the college variable. This result can be explained by the fact that university students, by their different specializations and colleges, taking university education under the same conditions and with the same teaching methods.

Question three: Calculate the frequencies and percentages of the responses of the study sample individuals to the paragraphs of the brain dominance instrument, and Table (3) clarifies that.

Table 3. Frequencies and percentages of study sample individuals' responses for brain dominance patterns paragraphs.

\begin{tabular}{|l|c|c|c|c|}
\hline \multicolumn{1}{|c|}{ Pattern } & Frequency & Percentage & Chi-Square & Significant \\
\hline Left & 247 & 28.10 & & \\
\hline Right & 503 & 57.10 & $242.473^{*}$ & 0.000 \\
\hline Integrated & 130 & 14.80 & & \\
\hline
\end{tabular}

*Statistically significant at the level of statistical significance $(\alpha=0.05)$

It is noticed from table (3) that the prevailing pattern of brain dominance among Jordanian university students is (right) with a percentage of (57.10) with (503) students out of (880) students, followed by (left) pattern with a frequency of (247) and a percentage of (28.10), and finally the (integrated) pattern with a frequency of (130) and a percentage of (14.80). Also, statistical significance was found at (0.05) for the pattern (right).

This result can be explained by the fact that the dominance of the right half, then the left, and then the integrated, does not mean that the pattern (right) of the brain is fully used, while the left is not used, and this result also indicates that the study sample individuals process non-verbal, spatial, sensory, holistic and symbolic information, And emotion, creativity and imagination.

Question four: The arithmetic means and standard deviations of the estimates of the study sample individuals were calculated for the Meta Cognition thinking instrument according to each field. Table No. (4) clarifies the results. 
Table 4. The arithmetic means and standard deviations of the study sample individuals estimates for the Meta Cognition thinking instrument according to each field.

\begin{tabular}{|c|c|c|c|c|c|c|c|c|c|}
\hline \multirow{3}{*}{ Field } & \multirow{3}{*}{ College } & \multirow{3}{*}{ Mean } & \multirow{3}{*}{ SD } & \multicolumn{4}{|c|}{ Gender } & \multirow{2}{*}{\multicolumn{2}{|c|}{ Total }} \\
\hline & & & & \multicolumn{2}{|c|}{ Male } & \multicolumn{2}{|c|}{ Female } & & \\
\hline & & & & SMA & $S D$ & $S M A$ & $S D$ & $S M A$ & $S D$ \\
\hline \multirow{3}{*}{\begin{tabular}{|l|} 
Knowing \\
Knowledge
\end{tabular}} & Humanities & 3.46 & 0.54 & 3.88 & 0.69 & 3.96 & 0.69 & 3.66 & 0.64 \\
\hline & Scientific & 3.52 & 0.51 & 3.45 & 0.59 & 3.53 & 0.61 & 3.50 & 0.54 \\
\hline & Total & 3.48 & 0.52 & 3.64 & 0.66 & 3.71 & 0.67 & 3.58 & 0.60 \\
\hline \multirow{3}{*}{$\begin{array}{l}\text { Regulation } \\
\text { knowledge }\end{array}$} & Humanities & 3.70 & 0.64 & 3.67 & 0.62 & 3.75 & 0.61 & 3.72 & 0.61 \\
\hline & Scientific & 3.75 & 0.63 & 3.47 & 0.66 & 3.55 & 0.67 & 3.65 & 0.65 \\
\hline & Total & 3.73 & 0.61 & 3.56 & 0.67 & 3.55 & 0.65 & 3.69 & 0.64 \\
\hline \multirow{3}{*}{$\begin{array}{l}\text { Processing } \\
\text { knowledge }\end{array}$} & Humanities & 3.51 & 0.66 & 3.77 & 0.86 & 3.64 & 0.85 & 3.63 & 0.78 \\
\hline & Scientific & 3.28 & 0.61 & 3.28 & 0.57 & 3.85 & 0.59 & 3.36 & 0.58 \\
\hline & Total & 3.44 & 0.61 & 3.50 & 0.75 & 3.58 & 0.75 & 3.49 & 0.68 \\
\hline
\end{tabular}

It is noticed from Table (4) that there are apparent differences between the arithmetic means of the study sample individuals' estimates for each field of Meta Cognition thinking scale according to the college variable. To determine the statistical significance of these apparent differences, two-way ANOVA analysis was applied. Table (5) clarifies the results of the analysis.

Table 5. One way ANOVA Analysis of the study samples estimate on each domain of meta-cognitive scale

\begin{tabular}{|c|c|c|c|c|c|c|}
\hline Source of variance & Field & $\begin{array}{c}\text { Sum of } \\
\text { squares }\end{array}$ & df & $\begin{array}{c}\text { Mean } \\
\text { squares }\end{array}$ & $F$ value & $\begin{array}{c}\text { Level of } \\
\text { Sig } \\
\end{array}$ \\
\hline \multirow{3}{*}{$\begin{array}{l}\text { Gender } \\
\text { Hollings } \\
\text { Trace }=0.072\end{array}$} & Knowing Knowledge & 10.665 & 1 & 10.665 & $30.743^{*}$ & 0.000 \\
\hline & Regulation knowledge & 0.816 & 1 & 0.816 & 1.857 & 0.162 \\
\hline & Processing knowledge & 4.66 & 1 & 4.66 & $9.998 *$ & 0.001 \\
\hline \multirow{3}{*}{$\begin{array}{l}\text { College } \\
\text { Hollings } \\
\text { Trace }=0.072\end{array}$} & Knowing Knowledge & 6.40 & 1 & 6.40 & 17.982 & 0.000 \\
\hline & Regulation knowledge & 0.797 & 1 & 0.797 & 1.940 & 0.163 \\
\hline & Processing knowledge & 13.929 & 1 & 13.929 & $31.169 *$ & 0.000 \\
\hline \multirow{3}{*}{$\begin{array}{l}\text { Collegexgender } \\
\text { Wilks,Lambda= } \\
0.961\end{array}$} & Knowing Knowledge & 6.989 & 1 & 6.989 & $21.842 *$ & 0.000 \\
\hline & Regulation knowledge & 2.415 & 1 & 2.415 & $5.742 *$ & 0.018 \\
\hline & Processing knowledge & 3.989 & 1 & 3.989 & $9.763 *$ & 0.002 \\
\hline \multirow[t]{3}{*}{ Error } & Knowing Knowledge & 198.732 & 879 & 0.337 & & \\
\hline & Regulation knowledge & 241.989 & 879 & 0.337 & & \\
\hline & Processing knowledge & 267.289 & 879 & 0.416 & & \\
\hline \multirow[t]{3}{*}{ Adjusted Total } & Knowing Knowledge & 219.539 & 879 & & & \\
\hline & Regulation knowledge & 247.938 & 879 & & & \\
\hline & Processing knowledge & 278.454 & 879 & & & \\
\hline
\end{tabular}

*Statistically significant at the level of statistical significance $(\alpha=0.05)$.

Table (5): Two-way MANOVA analysis to determine the statistical significance of the apparent differences of the estimates of the study sample individuals on each domain of the Meta Cognition thinking scale according to the variable of college and gender. 
It is noted from Table (5) that there are statistically significant differences at the level of significance $(\alpha=0.05)$ between the two arithmetic means of the study sample individuals' estimates in the two fields (cognitive organizing and cognitive processing), due to the gender variable, and from the table of arithmetic means, it is clear that the difference is in favor of females. This result can be explained by the fact that the female students are characterized with the planned and organized work, and do not rely on guesswork, with an account of the chronology or according to importance more than the male students.

It is also noted from this table that there are differences between the two arithmetic means of the study sample individuals' estimates in the two fields (cognitive organizing and cognitive processing) due to the variable of the college, and in favor of the human faculties, and this can be attributed to the fact that the student in the human faculties is interested in the general meaning and not in the exact details that the student of scientific colleges interests in.

Question five: Calculating the arithmetic means and standard deviations of the study sample individuals' estimates on the scale of Meta Cognition thinking as a whole, according to a variable (brain dominance pattern). Table (6) shows the results of the analysis.

Table 6. The arithmetic means and standard deviations of the study sample individuals' estimates on the Meta Cognition thinking scale as a whole, according to the brain dominance pattern

\begin{tabular}{|l|c|c|}
\hline \multicolumn{1}{|c|}{ Brain dominance pattern } & SMA & SD \\
\hline Left & 3.68 & 0.51 \\
\hline Right & 3.58 & 0.44 \\
\hline Integrated & 3.49 & 0.52 \\
\hline
\end{tabular}

It is noticed from table (6) that there are apparent differences between the arithmetic means of the study sample individuals' estimates on the scale of Meta Cognition thinking as a whole, according to the variable of the brain dominance pattern. To determine the statistical significance of these apparent differences, one-way ANOVA analysis was applied, and table (7) clarifies the results.

Table 7. One-way ANOVA analysis of the arithmetic means of the study sample individuals' estimates on the Meta Cognition thinking scale as a whole according to the brain dominance pattern.

\begin{tabular}{|l|c|c|c|c|c|}
\hline \multicolumn{1}{|c|}{ Variable } & Sum of squares & df & Mean squares & F value & Level of Sig \\
\hline Between groups & 2.243 & 2 & 1.131 & $5.214^{*}$ & 0.006 \\
\hline Within groups & 57.598 & 878 & 0.216 & & \\
\hline Total & 129.841 & 880 & & & \\
\hline
\end{tabular}

*Statistically significant at the level of statistical significance $(\alpha=0.05)$.

It is noted from table (7) that there are statistically significant differences at the level of significance $(\alpha=0.05)$ between the arithmetic means of the study sample individuals' estimates on the scale of Meta Cognition thinking as a whole, due to the variable of the brain dominance pattern, where the value of the statistical significance 
was (0.006) which it is lower than the level of significance $(\alpha=0.05)$. To find out these statistically significant differences are in favor of whom, Scheffe' Test was used for dimensional comparisons. Table (8) clarifies the results.

Table 8. The result of the Scheffe Test for dimensional comparisons of arithmetic means the study sample individuals' estimates on the Meta Cognition thinking scale as a whole according to the brain dominance variable.

\begin{tabular}{|l|c|c|c|}
\hline \multicolumn{1}{|c|}{ Brain dominance pattern } & SMA & Right & Left \\
\hline Left & 3.68 & 0.11 & $0.22 *$ \\
\hline Right & 3.58 & & 0.10 \\
\hline Integrated & 3.47 & & \\
\hline
\end{tabular}

*Statistically significant at the level of statistical significance $(\alpha=0.05)$.

It is noticed from Table (8) that there is a statistically significant difference at the level of statistical significance $(\alpha=0.05)$ in Meta Cognition thinking among students with the (left) brain dominance pattern compared to those with the (integrated) brain dominance pattern, and in favor of those with the (left) brain dominance pattern. This means that the level of Meta Cognition thinking is higher than that of people with the pattern (right). These results are consistent with what is stated in the results of the studies, which indicate the control of the individual over his thoughts and dominant over them, and this is what characterizes those with (left) brain dominance pattern, as they are characterized by the accurate, systematic and logical thinking, and a preference for organized and planned actions.

\section{Conclusion}

Based on the study results, the researcher recommends university professors to employ learning and teaching strategies that simulate the two brain halves, and the importance of investing the high level of Meta Cognition thinking in increasing psychological, social and academic compatibility through the integration of students in planned educational activities and specially designed research processes so.

\section{$5 \quad$ References}

[1] L. Costa, L., and B. Kallick. (2001). What are Habits of Mind? Retrieved Mar 7, 2009, from http//www.habits - of - mind.net/ what are.

[2] A. Zahriy \& A. Sabah.(2016).Brain Dominance and its relationship to creative thinking among University students in Jordan in the light of some demographic variables .Jordanian Journal in Educational Science. Vol 9 Issue(2).pp.239-254.

[3] J.H. Flavell.(1979). Meta cognition and cognitive monitoring. American Psychologist, 34, 906-911.

[4] G. Wallach, L. Miller. (1998). Language Intervention and Academic Success. Boston, M. A., College Hill Press.

[5] S. Graham. (1997). Effective Language Learning, Clevedon, England: Multilingual Maters. 
[6] J. Otero, J., Campanario and K. Hopkins. (1992). The relationship between academic achievement and met cognitive comprehension monitoring ability of Spanish secondary school students. Educational and Psychological Measurement, 52 (2), 419-430. https://doi.org/10.1177/0013164492052002017

[7] S. Turan and O. Demirel. (2010). In what level and how medical students use met cognition? A case from Hacettepe University. Proscenia Social and Behavioral Sciences, 2 (2), 948-952. https://doi.org/10.1016/j.sbspro.2010.03.132

[8] D. Sousa. (2001). How the brain learns. Reston, VA: National Association of Secondary school principals.

[9] R. Nageswara.(2018). Metacognition and hemisphere Dominance among the High School Students. International Journal of Creative Research Thoughts (IJCRT). Vol 6,Issue 1.p1246-1270.

[10] J. Anderson. (1990). Cognitive psychology and its implications, 3rd ed, New York: Freeman.

[11] ]L. Keita,\& N. Bedoin.(2011).Hemispheric asymmetries in hierarchical processing are modulated by stimulus categories and their predictability, 16(3),333- https://doi.org/10. $1080 / 13576501003671603$

[12] A. Abrahm , K. p ierrtiz, K. Thybuchm ,B. Rutter, S. Kroger, R Weckendike, R. Stark \& C. Windman.(2012). Creativity and the brain : uncovering the neural signature of conceptual expansion. Necropsy chologia, (50)(8), 1906-1917. https://doi.org/10.1016/j.neuropsychologia.2012.04.015

[13] M. Gluck, E. Mercado \& C.E. Myers, C.E. (2008). Learning and Memory- from Brain to Behavior. New York: Worth Publishers.

[14] R.L. Solos. (2004). Cognitive Psychology. 6th. ed. Singapore: Pearson Education College Students Journal, Vol.35(2). p.193 Issue, 01463934.EBSCO.

[15] O. Meryem. (2016). The Correlation between Brain Dominance and Language Learning Strategy Use of English Preparatory School Students. Approval of the Institute of Graduate Studies and Research. http://i-rep.emu.edu.tr.

[16] Springer. \& G, Deutsh. (2003). Company and Hagerman. Brain Right Brain Left).

[17] R. A. Hargrove, and J. L. Nietfeld. (2015). The impact of metacognitive instruction oncreative problem solving. J. Exp. Educ. 83, 291-318. Doi 10.1080/00220973.2013.876604.

[18] J. Laavch. (1997). Cerebra Hamisphericity, College Major and Occupational Choices. Journal of Creative Behavior,25(3).218-222.

[19] A. Saleh, (2001). Brain Hamisphericity and Academic Majors: A correlation st

[20] M. Al Baili. (1993): Inferred Hemispheric Thinking style, Gend and Academic Major among United Arab Emirates College students, Perceptual and motor skills, 76:971-977. https://doi.org/10.2466/pms.1993.76.3.971

[21] K. Barbara. (2002): Inside the brain-based learning classroom, retrieved from: www.smp. gseis.ucla.edu/smp/publications/quarterlyfram/v4/v4n3/bb1.vl ass.htm

[22] N. M Muhammad. (004). The effect of a teaching - learning programme based on the serious creativity theory on developing mental motivation of undergraduate students with left brain hemisphere dominance. Doctoral Dissertation, Amman Arab University.

[23] Perez. 17 of processing emotional of lateralization depressed and anxious diagnosed clinically and Natural of Journal Asian. patients male .141-120), 3 (2,Sciences Applied.

[24] M. Oflaz. (2011). The effect of right and left-brain dominance in language learning, Proscenia social and Behavioural Sciences, 15, 1507-1513. https://doi.org/10.1016/j.sbspro. $\underline{2011.03 .320}$ 
[25] N. Aljaberi \& E. Gheith. (2014). The relationship between the University Student's Level of Meta cognitive Thinking and their Ability to solve Mathematical and Scientific Problems, Research on.

[26] A. Nizar. (2017). The Patterns of Brain Dominance Prevailing and its Relation to Meta Cognitive Thinking for Students of Hail University. Journal of Education Faculty. AlAzhar University, (176) p.753-785.

[27] Azhar, Rasheed (2013). The level of the meta cognitive thinking for Baghdad University students. Journal Of Educational and Psychological Researches Volume 10, Issue39, PP.188-218.

[28] A. Aljarrah, A. Obiedat.(2011). Met cognitive Thinking Level Amongst a Sample of Yarmouk University Students in the Light of Some Variables. Jordanian Journal of Educational Sciences. Vol (7), N (2). P.154-162.

[29] A. Afaf. (2017). Brain dominance and the correlation with learning styles, choosing specialization and academic level among university students. International Journal for Research in Education (IJRE). Vol41, Issue (1).

[30] A. Kumar. (1998). The Influence of Met cognition on Managerial Hiring Decision Makin Implications for Management Development. Unpublished Doctoral Dissertation, Virginia Polytechnic Institute and State University.

\section{Author}

Dr. Hussain Aburayash, Assistant proof at the Arab Open University, specialized in educational psychology(Teaching \& Learning). I have an interest in thinking studies and their application in instruction

Dr. Hussain Aburayash, Assistant proof at the Arab Open University, Specialized in educational psychology(Teaching \& Learning).I have an interest in thinking studies and their application in instruction Article submitted 2021-02-13. Resubmitted 2021-04-06 